\title{
Notas breves sobre las medidas tributarias en el Ecuador bajo la coyuntura de la crisis actual y el marco constitucional que las delimita.
}

Brief notes on tax measures in Ecuador under the crisis and the constitutional framework that delimits them

\author{
Dr. Sandro Vallejo Aristizábal* \\ Pontificia Universidad Católica del Ecuador \\ Infomación del Artículo \\ Original - Ruptura, 2020 \\ Artículo recibido / Received: 29 de junio, 2020 \\ Artículo aceptado / Accepted: 2 de diciembre, 2020
}

\section{Citación}

Vallejo, S. (2020). Notas breves sobre las medidas tributarias en el Ecuador bajo la coyuntura de la crisis actual y el marco constitucional que las delimita. Revista Ruptura de la Asociación Escuela de Derecho PUCE. Edición 2020, p (377-400).

DOI: $10.26807 /$ rr.vi02.60

Resumen: Los sistemas tributarios implican un conjunto de impuestos articulados de forma coherente con la realidad social y económica de un Estado, y definidos bajo su marco jurídico. Para entender esto, es necesario conocer, al menos de forma superficial, como gravan los impuestos a las manifestaciones de riqueza. En el

* Abogado y Doctor en Jurisprudencia, por la Pontificia Universidad Católica del Ecuador. Especialista en Derecho Tributario por la Universidad Andina Simón Bolívar. Socio de SMARTLEX, se ha desempeñado como Asesor Tributario y Director Financiero Tributario del Municipio Metropolitano de Quito. Diez años de experiencia en el Servicio de Rentas Internas. Profesor de la Pontificia Universidad Católica del Ecuador, en Derecho Tributario, Derecho Registral e Inmobiliario. Consultor externo del BdE para la gestión de cobranza de impuestos municipales. 
caso ecuatoriano, el marco constitucional de nuestro sistema tributario, no se refleja adecuadamente en las políticas adoptadas por el gobierno, situación que se agrava en el escenario de la crisis actual; por lo que se requiere reconducir las propuestas de reforma tributaria para lograr una articulación con el marco normativo vigente; pero también, entendiendo la realidad social y económica, recogiendo en lo posible propuestas técnicas que se vienen dando.

Palabras clave: Sistema Tributario, Impuestos, equidad, eficiencia, Renta.

Abstract: Tax systems is made up by taxes articulated consistently with the social and economic reality of a country and delimited by legal framework. To understand this, it is necessary to know, how taxes are imposed on manifestations of wealth. In Ecuador, the constitutional framework of our tax system is not adequately reflected in the policies adopted by the government, a situation that is aggravated in the current crisis context. It is the reason why it is necessary to redirect the proposals for tax reform to achieve an articulation with the current regulatory framework, but also understanding the social and economic reality, gathering as far as possible technical proposals that have been taking place.

Keyword: Tax system, Taxes, equality, efficiency, income.

\section{Introducción}

Con la finalidad de analizar el contexto ecuatoriano en materia tributaria a la luz de las medidas adoptadas durante la pandemia, se realizará una descripción del sistema tributario vigente, así como de los fines fiscales y extrafiscales de la política tributaria. Estructura que se complementa con los principios que rigen a los impuestos. En un segundo punto se abordan los principios de Equidad y Eficiencia, los cuales brindan el marco de análisis sobre las decisiones adoptadas por el Gobierno, tomando en cuenta la situación social y la coyuntura económica por la que atraviesa el país. En base a lo antedicho en el punto tres se aborda la perspectiva constitucional que debe tener la política tributaria para 
analizar en el punto cuatro la compleja situación de reforma tributaria que vive el Ecuador, donde se concluye que la propuesta para sobrellevar la crisis debe contemplar medidas que no perjudiquen la recuperación, que tengan en cuenta el principio de equidad y que diferencien adecuadamente las medidas que deben ser transitorias de las permanentes.

\section{Impuestos fiscales y política fiscal}

Jorge Cosulich, refiriendo a Schmoldrs, afirma que un sistema tributario "implica un conjunto ordenado, lógico y coherente de impuestos, en que cada uno se considera parte de un todo armónicamente relacionado" (2009, p.2), el cual actúa como instrumento de política fiscal, articulado con los objetivos de política económica, y con los objetivos sociales constitucionalmente establecidos. De igual forma, todo sistema tributario está condicionados por la realidad social y económica en la que se implementa.

Para entender esto, debe considerarse que, como afirma Eusebio González (1997), el sistema tributario tiene un fin fiscal o recaudatorio vinculado con el necesario financiamiento del Estado, que constituye la razón de ser principal de los tributos, sobre el que Juan Bautista Alberdi, citado por Casás, afirma: "El Tesoro y el Gobierno son dos hechos correlativos que se suponen mutuamente. El país que no puede costear su gobierno no puede existir como nación independiente" (2005, p.72).

Por otra parte, los Estados en ocasiones establecen otros objetivos que buscan alcanzar con la política tributaria. Estos son los denominados fines extrafiscales de la tributación, cuyo objetivo no es generar recursos para el financiamiento estatal, sino corregir externalidades, incentivando o desincentivando determinadas conductas de los miembros de la sociedad. En este grupo se ubican los denominados impuestos reguladores e impuestos Pigouvianos (Yañez, 2016), con amplio desarrollo en materia ambiental. El Art. 300 de nuestra Constitución, señala que: "la política tributaria promoverá la redistribución y estimulará el empleo, la producción de bienes y 
servicios, y conductas ecológicas, sociales y económicas responsables". Un ejemplo típico de un impuesto con fin fiscal es el IVA; en tanto que un ejemplo de un impuesto que persigue un fin extrafiscal puede encontrase en las reformas al Impuesto a los Consumos Especiales ICE, entre las que recientemente se incluyó como parte del hecho generador del tributo, al consumo de fundas plásticas. ${ }^{1}$

Más allá de si la finalidad es fiscal o extrafiscal, los impuestos gravan básicamente tres posibles manifestaciones de riqueza. En primer lugar, está el ingreso a la renta, que a su vez se manifiesta de diversas formas. El Art. 2 de nuestra ley de Régimen Tributario Interno, nos habla de ingresos del trabajo, del capital y de capital y trabajo (empresa); aunque, en el Art. 8, cuando se desarrollan los ingresos de fuente ecuatoriana, se incluye también el concepto de plusvalía y el incremento patrimonial, con independencia de su fuente productora. De otra parte, estos ingresos pueden ser atribuibles a personas naturales o sociedades ${ }^{2}$ lo que genera la existencia de distintos regímenes impositivos bajo la denominación de impuesto a la renta ${ }^{3}$.

Una segunda manifestación de la riqueza está dada por el gasto o el consumo, que también se expresan de diversas formas en la economía y que pueden ser gravados con impuestos en una o varias etapas de la cadena productiva; como pasa con el IVA, ICE y el ISD.

1 Incluso los impuestos pigouvianos, deben considerar manifestaciones de riqueza susceptibles de imposición, pues de otra forma se puede generar riesgos de afectar los principios de capacidad contributiva y de no confiscatoriedad.

2 El Art. 98 de la Ley de Régimen Tributario Interno, en concordancia con el Art. 24 del Código Tributario, definen a la sociedad, no solo como la persona jurídica sino incluso la sociedad de hecho y en general la unidad económica o patrimonio autónomo, distintos de sus miembros.

3 De sociedades, impuesto a la renta por herencias legados y donaciones, o el impuesto a la renta por ingresos provenientes de loterías, rifas, apuestas y similares o el incremento patrimonial no justificado. En el caso de las ganancias de capital pasivas derivadas de la plusvalía inmobiliaria, una parte entra dentro del sistema de renta global y otra corresponde al denominado impuesto de utilidad, creado en 1928 como impuesto fiscal y que partir de 1945 pasó a ser un impuesto municipal. 
Finalmente, la tercera manifestación de la riqueza es el patrimonio o capital, que al igual que en los casos anteriores, tiene diversas expresiones y efectos distintos, dependiendo si se trata del caso de sociedades con o sin fines de lucro, o de personas naturales o incluso, de que tipo de patrimonio se trata. En Ecuador, una variante de este impuesto es el impuesto predial urbano y rural que administran los GADs municipales.

Cabe señalar que estas tres manifestaciones se encuentran relacionadas entre sí, por lo que las medidas que afecten a una de ellas inciden de alguna manera en el comportamiento de las otras dos. De allí que no deba considerarse una medida sin evaluar los impactos generales en la economía y en cómo puede afectar las decisiones de los ciudadanos respeto de las otras manifestaciones. Estos aspectos inciden a la hora de definir una política tributaria.

Sobre las manifestaciones de riqueza señaladas, la mayoría de los sistemas tributarios a nivel mundial utilizan dos modelos de impuestos que son: los denominados impuestos directos y los denominados impuestos indirectos.

Héctor Villegas (2002) señala que la clasificación de impuestos directos e impuestos indirectos es la más antigua y generalizada y; apartándose de las digresiones terminológicas, afirma que los impuestos directos gravan la riqueza en sí misma, independientemente de su uso, en tanto que los indirectos gravan al uso que se hace de ella. De ello se deriva que los impuestos directos gravan la renta, utilidad o ingreso, así como el patrimonio; mientras que los impuestos indirectos gravan la transferencia o consumo de bienes y servicios.

Aunque no puede considerarse una regla absoluta, de manera general se considera que los impuestos directos, al gravar las manifestaciones inmediatas de la riqueza como son la renta y el patrimonio, son más redistributivos y equitativos (Martínez, 2015). Por su parte, los impuestos indirectos, por su carácter impersonal que se aplica a hechos abstractos, han sido tachados de injustos o inequitativos, porque no consultan la capacidad económica del contribuyente; ya que aplica la misma carga tributaria a contribuyentes con distintas 
capacidades de riqueza (Abello, 2016). De allí que los Estados deben evaluar el peso que dan a la tributación directa y la indirecta dentro de su política tributaria.

Las decisiones que adopte un gobierno en materia tributaria siempre implican un ejercicio de selección. Toda medida tributaria genera externalidades y afecta a una parte de la sociedad, sin que quepa hablar de un impuesto absolutamente neutral. Por ejemplo, una decisión de política fiscal que aumente el bienestar de los pobres, lo hará a costa de empeorar el de los ricos, por lo que cabe preguntar:

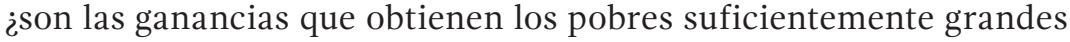
como para justificar las pérdidas que experimentan los ricos? (Stiglitz, 2000). Para responder esa pregunta debe tenerse en cuenta, entre otros factores, la realidad social, la coyuntura económica, la perspectiva ideológico-política y la noción de bienestar que tenga. Conceptos como equidad, eficiencia, redistribución, crecimiento y desarrollo están vinculados con las políticas fiscales y generan debates entre los actores políticos. A decir de Stiglitz (2000), hipotéticamente habría un consenso respecto de si hay un sistema tributario que mejore el bienestar de todos o que no empeore el de ninguno, el cual debería adoptarse; pero en la práctica esto no sucede, de allí que surjan discrepancias como la de los utilitaristas y rawlsanianos en torno a la noción de bienestar ${ }^{4}$.

La doctrina refiere ciertos atributos que debe tener en cuenta un sistema tributario. Adam Smith (1994), menciona los principios de igualdad, certeza, comodidad y economía, en tanto que Stiglitz (2000), además de justicia y eficiencia, incluye la flexibilidad, y la responsabilidad política (Accountability). A decir de Yañez (2015), todo sistema tributario debe considerar al menos criterios de equidad (justicia) y eficiencia, que son los dos objetivos económicos

4 Bajo la noción de justicia de Rawls (2006), debe darse una distribución apropiada de los beneficios y cargas, bajo los principios de equidad, imparcialidad y cooperación, priorizando el bienestar del individuo que se encuentra en peor situación, a diferencia de los utilitaristas que priorizan el bienestar de la mayoría de la población. 
deseables. En la práctica se suele tener que elegir entre uno de ellos y estar dispuesto a sacrificar en alguna magnitud el otro.

Sobre la eficiencia, Yañez (2015) señala que esta se define en términos de bienestar de la población. En ese sentido, una asignación eficiente de recursos implica la imposibilidad de que cualquier cambio en la asignación de recursos, deje en una mejor posición a una persona o varias personas, sin dejar a nadie en peor situación. Por su lado, el concepto de equidad se vincula con la noción de justicia y consiste principalmente en que la carga tributaria ha de ser repartida justamente.

Un criterio que necesariamente debe tenerse en cuenta al momento de diseñar una política tributaria es el principio doctrinario de capacidad contributiva; pues, pese a que no se hace una mención específica de él dentro del texto constitucional, este principio constituye el eje transversal de todos los demás. Sobre el fundamento de este principio, Ernesto Leujene Valcárcel, señala que: "En efecto, en primer lugar, se establece la obligación básica de todos los ciudadanos de contribuir al sostenimiento del gasto público, contribución que se hará de acuerdo con la capacidad contributiva de ellos." (2001, p.229). Por su parte Franchesco Moschetti (2001) señala:

La capacidad contributiva es la idoneidad del sujeto a efectuar la prestación impuesta coactivamente y que tal idoneidad debe ser deducida de la existencia concreta del presupuesto económico relativo (...) Además ello 'condiciona' también 'la medida máxima del tributo en el sentido de que no puede fijarse en un nivel superior a la capacidad mostrada por el acto o el hecho' asumido como presupuesto (p.260).

Reconociendo su importancia, algunos autores cuestionan que la capacidad contributiva constituya en sí mismo un principio, sobre todo por considerar que carece de contenido real.

En cualquier caso, teniendo como base la capacidad contributiva, el diseño de una política tributaria de manera general debe buscar un razonable equilibrio entre eficiencia y equidad, y la forma en que la utilización de impuestos directos e indirectos contribuyan al mismo, atendiendo la situación social y la coyuntura económica. 
Sin embargo, en la práctica, dependiendo de las diversas perspectivas políticas e ideológicas, los gobiernos diseñan sus políticas fiscales otorgando, en unos casos, un mayor nivel de equidad; sacrificando eficiencia y en otros, haciendo lo contrario.

En ese contexto, la disyuntiva en materia tributaria, gira en torno a si se debe priorizar las necesidades presupuestarias del Estado o incentivar a uno o más de los agentes económicos, sacrificando el financiamiento público. Las repuestas ante dicha disyuntiva no son sencillas y en ningún caso resultarán totalmente acertadas o erradas, pues dependen de múltiples factores.

Desde una perspectiva ortodoxa, con la que suelen coincidir los sectores empresariales (El Comercio, 2017), la política fiscal debe fomentar el ahorro, reducir el gasto público, eliminar subsidios, liberalizar la economía e incentivar la inversión, mediante la reducción de impuestos empresariales, priorizando el crecimiento económico y la eficiencia. En esta perspectiva un déficit presupuestario debe corregirse con la reducción del gasto público.

En la otra esquina, los economistas heterodoxos (Plan V, 2018), entre otros aspectos, plantean una mayor inversión pública, renegociación de deuda pública, subsidios a sectores vulnerables, redistribución a través del aumento en el gasto público y aumento de ingresos tributarios, priorizando la equidad impositiva.

\section{Sobre Equidad y Eficiencia}

Es claro que no existe un sistema tributario ideal ni recetas universales. Reformas tributarias que han resultado convenientes en un país en momentos determinados, en otros países o momentos han resultado negativas, dependiendo de múltiples factores. 
Un error en que hemos incurrido más de una ocasión en nuestro país, partiendo de visiones desarrollistas ortodoxas ${ }^{5}$, ha sido el adoptar recetas que eventualmente se han mostrado como efectivas en determinadas economías, sin considerar las variables que rodearon dichas medidas, asumiendo que nuestra economía necesariamente deberá transitar por idénticos caminos. Precisamente, la Carta de Intención suscrita por el Ecuador con el Fondo Monetario Internacional FMI (Ministerio de Economía y Finanzas, 2019), propone, desde una visión ortodoxa, una reforma tributaria que tenga como objetivos priorizar la neutralidad y la eficiencia recaudatoria, ampliando la base impositiva; y dando prioridad a la tributación indirecta antes que directa.

Contrario a las propuestas del FMI, Abello (2016) afirma que se debe priorizar la equidad tributaria, es decir que "los que poseen el mayor ingreso o riqueza pagan la mayor parte del impuesto, independientemente de los beneficios que reciban del gasto de estos fondos" (p.60). Para Yañez (2015), los conceptos de equidad y de eficiencia, son comunes en las distintas visiones de bienestar y en un ideal, debería aspirarse a un máximo de equidad y un máximo de eficiencia.

En esa línea, Ruiz Almendral (2004), señala que una revisión de los sistemas tributarios europeos e incluso norteamericanos del segundo y tercer cuarto del siglo anterior, evidencian la relación entre los impuestos progresivos; principalmente las rentas de las personas físicas, en algunos casos con tasas marginales muy elevadas y una política de gasto social profunda que permitió un crecimiento económico sostenido y sobre todo, la disminución de las inequidades sociales de manera determinante.

5 En los años 60, sostenía que, para llegar a ser desarrolladas, todas las sociedades atraviesan una de las cinco fases siguientes: la sociedad tradicional, las condiciones previas al despegue, el despegue, el progreso hacia la madurez y la era del consumo de masas. En esa línea, Harley Hinrichs (1965) adjudicaba a cada una, un específico sistema tributario. 
En la misma línea en las XXIV Jornadas Latinoamericanas de Derecho Tributario (2008), se concluyó que, para contar con los recursos para el desarrollo económico, se debe adoptar formas de imposición sobre la renta que garanticen los principios de progresividad y justicia tributaria que compatibilicen la eficiencia económica y recaudatoria.

Como instrumentos de política tributaria de mayor aplicación a nivel mundial, tenemos entre los impuestos directos, el impuesto sobre la Renta; y en sus diversas variantes y en menor medida, los impuestos sobre el patrimonio. Del otro lado, entre los impuestos indirectos de mayor difusión, se encuentran los impuestos al comercio exterior o aranceles, y los impuestos a las ventas o al consumo, entre los que destacan los impuestos sobre el valor añadido o agregado y los impuestos a los consumos suntuarios o especiales. Con una menor relevancia fiscal, tenemos los denominados impuestos pigouvianos y las contribuciones a la seguridad social ${ }^{6}$.

Como hemos señalado, la política tributaria, además de respaldarse en criterios técnicos, debe considerar la situación social y la coyuntura económica como un condicionante y en tal virtud, evitar aplicar recetas predefinidas.

Las propuestas de reformas tributarias incluidas en la carta de intención suscrita por el Gobierno Ecuatoriano en 2019 parecen no haber evaluado adecuadamente estos factores, principalmente lo relativo a la equidad. En nuestro país, los niveles de desigualdad son enormes. Según un estudio de la Facultad de Economía de la U. Central, sobre datos de la ENEDMU (Báez, 2019), el 10\% de la población más rica, posee una riqueza de más del doble del $40 \%$ de la población más pobre. Si se considera los criterios de bienestar, basado en la encuesta de estratificación del nivel socioeconómico efectuada por el (INEC, 2011), el 2\% de la población más rica, mantiene un puntaje

6 Aunque no se trata propiamente de un impuesto dada su incidencia, los aportes a la Seguridad Social suelen incluirse dentro de los análisis de presión fiscal de los países. 
superior al $64 \%$ de la población más pobre, lo que evidencia importantes niveles de inequidad social y económica en el Ecuador.

En todo caso, según información publicada por el Banco Mundial (2019) sobre desigualdad en América Latina, Ecuador se encuentra en la media de la Región, aunque muy por debajo de países desarrollados como Dinamarca o Islandia a nivel de la OCDE (2015).

Por otra parte, según información de la OCDE (2019) sobre presión fiscal en América Latina, el Ecuador con $20 \%$ está un poco por debajo de la media de América Latina y Caribe que se ubica en el 22,8\%; muy por debajo de la media de los países miembros de la OCDE, con un promedio del $34.8 \%$. Adicionalmente, según datos oficiales del SRI (2019), la recaudación de IVA hasta el año 2019 seguía estando por encima de la del Impuesto a la Renta.

\section{Marco Constitucional de la Política Tributaria}

Desde una perspectiva jurídica, nuestro sistema tributario debería guardar coherencia con los postulados constitucionales esenciales y los objetivos de desarrollo y de una política de Estado que debe definir sus prioridades en base a tales postulados. El Art. 3 de nuestra Constitución, entre los deberes primordiales del Estado incluye en su numeral 5, que para acceder al buen vivir o Sumak Kawsay, se debe erradicar la pobreza, promover el desarrollo sustentable y la redistribución equitativa de los recursos y la riqueza, promover el desarrollo equitativo y solidario de todo el territorio. De igual manera en el capítulo de soberanía económica, el artículo 283 señala:

El sistema económico es social y solidario; reconoce al ser humano como sujeto y fin; propende a una relación dinámica y equilibrada entre sociedad, Estado y mercado, en armonía con la naturaleza; y tiene por objetivo garantizar la producción y reproducción de las condiciones materiales e inmateriales que posibiliten el buen vivir. (CRE, 2008).

Por su parte el Art. 300 de la Constitución señala que: "el régimen tributario se regirá por los principios de generalidad, progresividad, 
eficiencia, simplicidad administrativa, irretroactividad, equidad, transparencia y suficiencia recaudatoria", disponiendo que se debe priorizar los impuestos directos y progresivos y que la política tributaria debe promover la redistribución y estimular el empleo, la producción de bienes y servicios, conductas ecológicas, sociales y económicas responsables.

La Corte Constitucional del Ecuador (2011) sobre el principio de equidad ha manifestado:

En el ámbito tributario, la equidad atiende a dos ámbitos: el horizontal y vertical. Por el primer ámbito se entiende que las personas con capacidad económica igual deben contribuir de igual manera, es decir, se relaciona con los principios de generalidad e igualdad formal; y por el ámbito de equidad vertical se entiende que las personas con mayor capacidad económica deben contribuir en mayor medida, lo que tiene relación con los principios constitucionales de igualdad material y progresividad del sistema tributario (Sentencia No. 004-11-SIN-CC).

\section{Que esperar en la coyuntura actual}

La crisis sanitaria provocada por el virus del SRAS-CoV-2 es, en buena medida, causante de la peor crisis económica a nivel mundial en los últimos 50 años. Según datos de CEPAL (2020), la contracción del PIB mundial de este año será mayor a la observada en la crisis financiera global de 2008. Todas las regiones del planeta experimentarán un decrecimiento significativo del PIB, con un promedio a nivel mundial del -2\%. En el caso de América Latina la situación se presenta aún más grave, con un promedio del $-5.3 \%$, siendo Ecuador uno de los países con un mayor decrecimiento estimado, en alrededor del $-6.5 \%$.

En el caso ecuatoriano, ese escenario agravó una situación que se presentaba negativa desde el año 2018; además del impacto en las economías de las empresas y las personas, la crisis ha implicado un incremento del déficit fiscal. Aunque la información oficial no es del todo consistente, algunas declaraciones de las autoridades económicas estiman un posible déficit presupuestario para este año cercano a 
los 10.000 millones de dólares y con un peso de deuda pública enorme en los próximos años.

Mirando desde la perspectiva tributaria, la coyuntura actual implica dos escenarios distintos: las medidas tributarias durante la crisis de la pandemia que puede durar varios meses y las medidas tributarias de mediano plazo, es decir, posteriores a la crisis.

Sobre el primer escenario, el gobierno, ante la falta de apoyo político en la Asamblea Nacional, declinó su idea de imponer nuevos impuestos temporales para financiar parte del déficit ${ }^{7}$, con lo cual se sumó a la tendencia mayoritaria a nivel mundial de no imponer nuevas cargas tributarias en medio de la crisis y tomar algunas medidas de alivio a la falta de liquidez, como el diferimiento de impuestos; adoptando, por otro lado, medidas que han generado que el gran peso del financiamiento, hasta el momento, recaiga en los empleados públicos de la función ejecutiva ${ }^{8}$.

El escenario post crisis es distinto, sobre todo considerando la grave situación fiscal actual y próxima que obligará al Ecuador, al igual que la mayoría de Estados, a adoptar medidas de ajuste tributario en el mediano plazo, tomando en cuenta que la mayoría de los países ha incrementado su gasto público para enfrentar la crisis actual?.

7 El 22 de junio se publicó en Registro Oficial Nro. S-229 la "Ley Orgánica de Apoyo Humanitario para combatir la crisis sanitaria derivada del COVID-19”, en cuyo proyecto inicial se incluía un capítulo con tres impuestos (Contribuciones temporales) que fueron retirados antes de que le pleno lo conociera en segundo debate.

8 Mediante Decreto Ejecutivo Nro. 1053, de 19 de mayo de 2020 y posterior Acuerdo Ministerial Nro. MDT-2020-117, se dispuso la reducción de la jornada laboral del sector público, que implicó una reducción de las remuneraciones en aproximadamente un $17 \%$ para los empleados públicos de la función ejecutiva.

9 Cabe señalar que según información publicada por el BID, hasta el 15 de abril, Ecuador era el país de la región que menos recursos públicos había anunciado para atacar la Pandemia en porcentaje del PIB (Pineda, Pessino, \& Rastelett, 2020), esto en parte obedece a que se priorizó el pago de obligaciones con acreedores privados de deuda pública (tenedores de bonos). 
El Centro Interamericano de Administraciones Tributarias CIAT (González, 2020), en un documento de trabajo, propone algunas medidas de mediano plazo que incluyen la ampliación de las bases de contribuyentes, eliminación de escudos fiscales e incremento de tasas progresivas para las rentas y patrimonios superiores, entre otras medidas.

Por su parte, el Fondo Monetario Internacional, en una nota publicada recientemente, en el contexto de esta crisis, incluye entre las recomendaciones "Considerar aumentos de las tasas en los tramos superiores del impuesto sobre la renta, del impuesto sobre la propiedad y del impuesto sobre el patrimonio, quizás a modo de 'sobretasa solidaria'" (FMI, 2020, p.3).

En un estudio sobre política fiscal frente a la crisis del SRAS-CoV-2, Díaz de Sarralde compara los efectos de esta crisis con los de una guerra y aunque establece claras e importantes diferencias, también encuentra aspectos comunes que podrían generar enseñanzas importantes de las respuestas dadas bajo tal analogía. Citando a Capella (2020), señala que "Los líderes deben elegir entre cuatro medios principales para financiar las guerras: impuestos, deuda interna, financiación externa, y monetización" (p.16). Cada una de estas alternativas tiene distintos costos y beneficios, dependiendo de la coyuntura de cada Estado. Siguiendo la perspectiva de Díaz de Sarralde, sobre los posibles escenarios, podemos señalar que, en el caso de la monetización, más allá de los riesgos que implica, resulta poco probable para utilizarla en Ecuador debido a nuestra economía dolarizada, incluso considerando un posible incremento de usos de moneda electrónica. Por otra parte, la posibilidad de incrementar el endeudamiento externo en el mediano plazo se presenta como una alternativa compleja y difícil, considerando los niveles a los que se ha llegado, a menos que se evidencie cambios importantes respecto de nuestra capacidad real de pago futuro. Algo similar sucede con el endeudamiento interno que también es elevado. Una particularidad del financiamiento público en Ecuador es el enorme peso de los ingresos petroleros que podría ser una alternativa, considerando que es posible que en el mediano plazo los precios se puedan estabilizar, sin embargo, creo que es importante para la salud de nuestra economía ir abandonando la idea de la dependencia excesiva de los ingresos petroleros. 
Esto deja al escenario de reforma tributaria en mediano plazo, como el más probable y real. En esa línea debería pensarse en un gran acuerdo nacional con todos los sectores políticos y sociales, con miras a una reforma profunda del sistema tributario ecuatoriano, pero adecuándolo a la realidad social y al marco constitucional; dejando de lado intereses de ciertos grupos que tengan real capacidad contributiva.

Díaz Serralde (2020) diferencia las posibles propuestas desde las perspectivas ortodoxa y heterodoxa, pero incluye algunas tendencias recientes que incluyen a los impuestos verdes, los denominados impuestos digitales, medidas contra la competencia fiscal ilegíti$\mathrm{ma}^{10}$, y propuestas de Imposición progresiva sobre las rentas altas e impuestos sobre la riqueza.

En un documento del BID (Brreix, Garcimartin \& Verdi, 2020), se propone, entre los aspectos más importantes para tener en cuenta en la post-crisis del COVID-19, el fortalecer los ingresos públicos, tomar medida que no perjudiquen la recuperación, tener en cuenta el principio de equidad y diferenciar adecuadamente las medidas son transitorias de las permanentes.

\section{A modo de conclusión.}

En la coyuntura actual de crisis, es necesario pensar en la necesidad de que se propicie una reforma tributaria en mediano plazo ${ }^{11}$, que considere la realidad social y económica y esté acorde nuestro marco constitucional. Frente a la necesidad de mejorar los ingresos

10 A partir de 2013, la OCDE ha trabajado en propuestas para combatir la Erosión de la base imponible y traslado de beneficios (BEPS por sus siglas en inglés) que tiene como objetivo principal el establecimiento de mecanismos por parte de los gobiernos y la coordinación entre ellos para tornarlas efectivas.

11 Probablemente para fines de este año debería pensarse ya en una propuesta que empiece a regir a partir del siguiente año, con alguna opción de diferir su vigencia unos meses más dependiendo del contexto económico, pero que ya debe empezar a discutirse. 
fiscales, ante la crítica situación actual, el Ecuador debería ir, al menos en buena parte, en una línea distinta a la propuesta en la carta de intención con el FMI, buscando un sistema tributario más progresivo y redistributivo ${ }^{12}$.

Esta visión va más allá de posiciones ideológicas, pues como se señaló, existen propuestas técnicas expuestas desde distintas visiones que tienen algunas coincidencias, como las anotadas en el presente artículo. En ese sentido, es importante pensar en reformas, algunas excepcionales de duración limitada y otras a los ingresos tributarios permanentes, que no necesariamente impliquen nuevos impuestos.

Conforme lo referimos anteriormente, entre los escenarios que el gobierno debería explorar en esta línea están, el incremento temporal de tarifas impositivas, o eliminar algunas exoneraciones o deducciones fiscales, o medidas que impliquen un incremento de las bases de contribuyentes, atacando principalmente las prácticas elusivas.

Como en su momento se propusiera en el marco de las XXIV Jornadas Latinoamericanas de Derecho Tributario (2008), los impuestos que gravan las distintas manifestaciones de renta pueden servir a los objetivos de distribución de la riqueza, considerando que las manifestaciones de renta constituyen una buena medida de la capacidad contributiva, y los impuestos que las gravan, pueden ser adaptados a las circunstancias individuales a través del manejo de las tasas marginales, impuestos a las ganancias extraordinarias ${ }^{13} \mathrm{O}$

12 Las decisiones adoptadas por el gobierno en los últimos dos años en materia tributaria evidencian un alejamiento de esta línea

13 No existe un criterio uniforme sobre lo que se debe entender como ganancia extraordinaria, pero han existido algunas experiencias a nivel internacional, relativas a coyunturas de altos precios de commodities como el petróleo que en el caso ecuatoriano se incluyó en la Ley Reformatoria para la Equidad Tributaria. También se puede mencionar la ganancia extraordinaria por ingresos derivados de la especulación inmobiliaria, que se implementó a través de un impuesto mal diseñado que finalmente fue derogado. 
a las denominadas rentas pasivas o de capital altas ${ }^{14}$, que bajo un criterio de progresividad eviten, en lo posible, una afectación a las rentas de trabajo y de empresa, que son vitales para la reactivación económica futura. En el marco de las mismas Jornadas, se propuso la incorporación de nuevas modalidades de imposición sobre la renta que compatibilicen la eficiencia económica y recaudatoria con la equidad impositiva y financiera, respetando la progresividad del sistema tributario (2008).

En la misma línea, es necesario considerar la disposición constitucional que proclama la priorización de los impuestos directos y progresivos; por tanto, analizar las propuestas que consideren este precepto constitucional y respecto del cual nos adherimos a los expertos respecto de sus recomendaciones en materia de impuesto a la renta e impuestos patrimoniales. Solo a manera de ejemplo, en torno a la idea de gravámenes progresivos a las grandes fortunas, economistas galardonados con premios nobel como Paul Krugman (2019) Joseph Stiglitz (2019), o los recientes ganadores Esther Duflo y Abhijit Banerjee, han defendido en más de una ocasión propuestas semejantes.

Es importante entender que, la idea de un sistema tributario progresivo no implica la desaparición de impuestos indirectos o proporcionales, sino una adecuada articulación entre los distintos impuestos. Por ejemplo, la adecuada aplicación de un impuesto a los consumos suntuarios, pese a ser esencialmente indirecto permite aportar a un esquema más progresivo en la medida que afectan a las clases más pudientes; igual mención puede efectuarse respecto del IVA si se racionaliza el régimen de tarifa $0 \%$.

14 Para definir adecuadamente una renta alta debería considerarse varios factores, tales como el índice de Gini, la participación del decil más alto en los ingresos del país y el peso relativo sobre la carga tributaria global. Al respecto resulta ilustrativo el estudio sobre la materia efectuado por la CEPAL (Gómez, Sabaíni \& Rossignolo, 2014). En Ecuador se podría incrementar las tarifas más altas hasta en un $10 \%$ adicional. 
Una alternativa que considero debe empezar a discutirse seriamente es la implementación de un impuesto patrimonial en los niveles de mayor concentración de riqueza, que no solo forma parte de las propuestas de exponentes de la nueva izquierda como Piketty ${ }^{15}$, sino incluso, como lo hemos señalado, al interior del propio FMI o del BID.

Sobre estos, considero que debe tenerse en cuenta, no solo el patrimonio inmobiliario, sino lo referente inversiones en el sistema financiero, en títulos valores y en otros intangibles. En la misma línea, debería pensarse en tarifas diferenciadas más altas para patrimonios en el exterior, y aquellos relacionados con paraísos fiscales.

En la implementación de un impuesto patrimonial, debería evaluarse esquemas de deducibilidad o de crédito tributario de los impuestos a la propiedad inmobiliaria existentes en la actualidad, o de algún porcentaje del impuesto a la renta, y que se establezcan tratamientos diferenciados a los patrimonios vinculados con actividades productivos respecto de los improductivos a efecto de fomentar la movilidad del capital y la inversión interna.

Por lo pronto, del gobierno no se ha escuchado una propuesta en esta materia, aunque además de lo comprometido en la carta de intención con el FMI, desde su grupo de asesores (El Universo, 2020), se ha mencionado la idea de incrementar el IVA al 14\%, propuesta que puede tener un mayor impacto fiscal, más aun considerando que el Ecuador posee una de las tarifas más bajas de la región, pero que puede ser no adecuado durante esta coyuntura, dado su carácter regresivo y que podría tener un efecto recesivo en el contexto actual, sin descontar la posibilidad de recurrir a él en mediano plazo.

Esto debe ir de la mano de una política de combate a la evasión y elusión tributaria a efecto de lograr una gestión más eficiente; además de una mejor política de gasto social. De acuerdo con los datos del incumplimiento tributario de la CEPAL (2019), la evasión afecta-

15 En su libro "El Capital del siglo XXI", como forma de combatir los elevados niveles de inequidad social, Piketty propone un impuesto a la riqueza, de alcance mundial. 
ba al $4 \%$ del PBI en el Impuesto sobre la Renta, y al 2,3\% del PBI en el IVA (p.37). Una mayor transparencia de la información tributaria, de la mano de mejoras en los análisis de riesgo y sistemas de cruces de información, sobre todo los que permitan comparar las variaciones patrimoniales de las personas naturales frente a los impuestos declarados, podrían aportar en esa línea. Desde una perspectiva más amplia, la administración tributaria debe continuar con las medidas iniciadas, sumándose a las iniciativas contra la erosión de la base imponible y el traslado de beneficios a nivel internacional ${ }^{16}$.

\section{Referencias Bibliográficas}

Abello Z, C. (2016). ¿Equidad o inequidad tributaria en el impuesto indirecto? (Dos Mil Tres Mil, Ed.) Unibague, 59-70. Obtenido de https://revistas. unibague.edu.co/dosmiltresmil/article/view/37

Báez, J. (2019). Desigualdad en Ecuador: La participación en el ingreso del decil más rico aumentó así como el Índice de Palma. (U. d. coyuntura., Editor, \& Facultad de Ciencieas Económicas.) Obtenido de https://coyunturaisip. wordpress.com/2019/09/12/desigualdad-en-ecuador-la-participacionen-el-ingreso-del-decil-mas-rico-aumento-asi-como-el-indice-de-palma/\#_ftn2

Banco Mundial. (2019). Los niveles de pobreza en América Latina. Obtenido de https://elordenmundial.com/mapas/pobreza-en-america-latina/

Barreix, A., Garcimartin, C., \& Verdi, M. (2020). Ideas para una mejor tributación en la post-crisis del COVID. Obtenido de https://blogs.iadb.org/gestion-fiscal/es/ideas-para-una-mejor-tributacion-post-crisis-coronavirus/

16 Los países de la OCDE (2014), han impulsado el proyecto BEPS ("Base Erosion and Profit Shifting”) que propone alternativas a los gobiernos para cerrar los vacíos en la normativa internacional que permiten a las empresas trasladar los beneficios de forma artificial a países de baja o nula tributación. 
Casás, J. O. (2005). Derechos y Garantías Constitucionales del Contribuyente. Buenos Aires: Ad Hoc.

CEPAL. (2019). Panorama fiscal de américa latina y el caribe 2019. Santiago: Naciones Unidas.

CEPAL. (2020). Informe sobre el impacto económico en América Latina y el Caribe de la enfermedad por coronavirus (COVID-19). Santiago: Naciones Unidas. Obtenido de https://repositorio.cepal.org/bitstream/handle/11362/45602/1/S2000313_es.pdf

Cosulich A, J. (2009). Concepto, elementos y principios generales y objetivos de los sistemas tributarios modernos. "Los principios de los sistemas y regímenes tributarios en el siglo XXI”. Quito: Universidad Andina Simón Bolívar. Obtenido de https://www.uasb.edu.ec/web/area-de-derecho/ contenido?foro-34los-principios-de-los-sistemas-y-regimenes-tributarios-en-el-siglo-xxi-34

Cosulich, J. (2009). Una visión de los Principios Generales de los Sistemas Tributarios Modernos. Universidad Andina Simón Bolívar (Ponencia s/e). Quito: s/e.

Díaz de Sarralde, S. (2020). ¿Cómo pagar las consecuencias de una pandemia? Obtenido de CIAT Documentos de Trabajo: https://www.ciat.org/Biblioteca/DocumentosdeTrabajo/2020/DT_01_2020_sarralde.pdf

El Comercio. (2017). Seis propuestas para reactivar la economía ecuatoriana. Obtenido de https://www.elcomercio.com/actualidad/propuestas-reactivacion-economia-ecuador-empresarios.html

EL PAÍS. (2020). Hay que subir los impuestos a los más ricos. Obtenido de https://elpais.com/elpais/2020/01/10/ideas/1578646387_428635.html

El Universo. (17 de junio de 2020). Alza del IVA al $14 \%$, propuesta de miembro del Consejo Asesor en Materia Económica del Gobierno. El Universo, pág. 2. 
FMI. (2020). Fiscal Affairs Cuestiones tributarias: Panorama General. Obtenido de https://www.imf.org/external/np/fad/news/links.htm/sp-special-series-on-covid-19-tax-and-customs-administration-responses.pdf

Gómez Sabaíni , J. C., \& Rossignolo, D. (2014). La tributación sobre las altas rentas en América Latina. Santiago de Chile: CEPAL.

González, D. (020). Nuevo orden tributario: La tributación y gestión post coronavirus en ALC. Obtenido de CIAT: https://www.ciat.org/nuevo-orden-tributario-la-tributacion-y-gestion-post-coronavirus-en-alc/

González, E. (1997). Derecho Tributario Tomo I. Salamanca: Plaza Universitaria Ediciones.

Hinrichs, H. H. (1965). Determinants of Government Revenue Shares Among Less Developed Countries. The Economic Journal, 75 (299), 546556. doi:10.2307/2228952

ILDT. (2008). Los principios tributarios ante las nuevas formas de imposición a la renta. En A. ILDT, Memorias de las XXIV Jornadas Latinoamericanas de Derecho Tributario. Margarita: Asociación Venezolana de Derecho Tributario.

INEC. (2011). Encuesta de Estratificación del nivel Socioeconómico. Obtenido de https://www.ecuadorencifras.gob.ec//documentos/web-inec/ Estadisticas_Sociales/Encuesta_Estratificacion_Nivel_Socioeconomico/111220_NSE_Presentacion.pdf

Instituto Latinoamericano de Derecho Tributario. (2008). XXIV Jornadas Latinoamericanas de Derecho Tributario. Tema II: Los Principios Tributarios ante las nuevas formas de Imposición a la Renta. Isla Margarita. Obtenido de http://www.iladt.org/frontend/xxxjornadas.aspx

Krugman, P. (2019). La economía de cobrar más impuestos a los que más ganan. New York Times. Version digital. Obtenido de https://www.nytimes.com/ es/2019/01/07/espanol/opinion/paul-krugman-economia-ricos.html 
Leujene Valcárcel, E. (2001). El Principio de Igualdad. En A. Amatucci, Tratado de Derecho Tributario (págs. 221-239). Bogotá: Temis.

Martínez Sánchez, C. (2015). Situación actual y perspectivas de los Impuestos sobre la Riqueza. Dossieres Economistas sin Fronteras: Fiscalidad: eficiencia y equidad, 21-27.

Ministerio de finanzas. (2019). Carta de Intención del Gobierno del Ecuador con el FMI. Oficio LOI-MEFP Español 201903182010 Article IV Report. ANEXO I Memorando de Políticas Económicas y Financieras. Obtenido de https://www.finanzas.gob.ec/wp-content/uploads/downloads/2019/03/LOI-MEFP-Espa\%C3\%B1ol.pdf

Moschetti, F. (2001). El Principio de la Capacidad Contributiva. En A. Amatucci, Tratado de Derecho Tributario (págs. 240-284). Bogotá: Temis.

OCDE . (2015). In It Together: Why Less Inequality Benefits All. Obtenido de https://www.oecd-ilibrary.org/employment/in-it-together-why-lessinequality-benefits-all_9789264235120-en

OCDE. (2014). Plan de acción contra la erosión de la base imponible y el traslado de beneficios. Paris: OCDE publishing. Obtenido de http://dx.doi. org/10.1787/9789264207813-es.

OCDE,CEPAL,BID,CIAT,ALC. (2019). Estadísticas tributarias en América Latina y el Caribe. Obtenido de http://www.oecd.org/tax/revenue-statistics-in-latin-america-and-the-caribbean-24104736.htm

Organización Mundial de la Salud. (s.f.). Los nombres de la enfermedad por coronavirus (COVID-19) y del virus que la causa. Obtenido de https:// www.who.int/es/emergencies/diseases/novel-coronavirus-2019/technical-guidance/naming-the-coronavirus-disease-(covid-2019)-andthe-virus-that-causes-it

Pineda, E., Pessino, C., \& Rastelett, A. (2020). Política y gestión fiscal durante la pandemiay la post-pandemia en América Latina yel Caribe. Obtenido de BID, Recaudando Bienestar: https://blogs.iadb.org/gestion-fiscal/es/politica-y-gestion-fiscal-durante-la-pandemia-y-la-post-pandemia-en-ame- 
rica-latina-y-el-caribe $/ ? \mathrm{j}=372803 \&$ sfmc_sub $=9986483 \& \mathrm{l}=295$ HT$\mathrm{ML} \& \mathrm{u}=7580730 \& \mathrm{mid}=100028582 \& \mathrm{jb}=13 \& \mathrm{fbclid}=I w A R 2 \mathrm{NXISS} 8 \mathrm{too}-$ qx_DMTz6QSZ2KbRE-eQsGomXFTU5Rh

Plan V. (2018). Las 10 críticas de los economistas de izquierda al programa económico. Obtenido de https://www.planv.com.ec/historias/sociedad/10-criticas-economistas-izquierda-al-programa-economico

Rawls, J. (2006). Teoría de la Justicia (segunda, sexta reimpresión ed.). México D.F.: Fondo de Cultura Económica.

Rostow, W. W. (1998). The Five Stages of Growth. En M. A. Seligson, \& J. T. Passé-Smith, Development and Underdevelopment: The Political Economy of Global Inequality. (págs. 203-210). Colorado: LYNNE RIENNER. Obtenido de https://www.rienner.com/title/Development_and_Underdevelopment_The_Political_Economy_of_Global_Inequality_5th_ edition

Ruiz A, V. (2004). Impuestos y Estado social. Obtenido de http://hdl.handle. net/10016/6931

Almendral, \& J. V. Troya, Finanzas Públicas y Constitución (págs. 9-60). Quito: Corporación Editora Nacional. Obtenido de http://hdl.handle. net/10016/6931

Sainz de Bujanda, F. (1979). Lecciones de Derecho Financiero. Madrid: Universidad Complutense.

Smith, A. (1994). La Riqueza de las naciones. Madrid: Alianza Editorial.

Servicios de Rentas Internas. (2019). Estadísticas de Recaudación 2019. Obtenido de https://www.sri.gob.ec/web/guest/estadisticas-generales-de-recaudacion-sri

Stiglitz, J. (2019). El capitalismo progresista no es un oxímoron. Ney York Times. Versión digital. Obtenido de https://www.nytimes.com/ es/2019/04/30/espanol/opinion/stiglitz-capitalismo.html 
Stiglitz, J. E. (2000). La economía del sector público (Tercera ed.). Barcelona: Antoni Bosch. Obtenido de https://desarrollomedellin.files.wordpress. com/2018/08/stiglitz-2000-tercera-edicion.pdf

Villegas, H. (2002). Curso de Finanzas Derecho Financiero y Tributario. (Octava ed.). Buenos Aires: Astrea. Obtenido de https://es.scribd.com/document/357545135/Curso-de-Finanzas-Derecho-Financiero-y-Tributario-Hector-B-Villegas-2

Yáñez H, J. (2015). Tributación: Equidad y/o eficiencia. Revista Estudios Tributarios, 223-259. Obtenido de http://repositorio.uchile.cl/handle/2250/138059

Yañez, J. (2016). Impuesto Pigouviano. Revista de Estudios Tributarios, 16, 159-197.

\section{Jurisprudencia Constitucional}

Corte Constitucional del Ecuador para el periodo de transición. Sentencia No. 004-11-SIN-CC. Caso No. 0069-09-IN de 18 de agosto de 2011. Juez ponente: Patricio Pazmiño Freire. 